\title{
TTR
}

Traduction, terminologie, re?daction

\section{In memoriam Elmar Tophoven}

\section{Antoine Berman}

Volume 2, numéro 1, 1er semestre 1989

Carrefours de la traduction

URI : https://id.erudit.org/iderudit/037029ar

DOI : https://doi.org/10.7202/037029ar

Aller au sommaire du numéro

Éditeur(s)

Association canadienne de traductologie

ISSN

0835-8443 (imprimé)

1708-2188 (numérique)

Découvrir la revue

Citer ce document

Berman, A. (1989). In memoriam Elmar Tophoven. TTR, 2(1), 9-9.

https://doi.org/10.7202/037029ar

Tous droits réservés (C) TTR: traduction, terminologie, rédaction - Les auteurs, d'utilisation que vous pouvez consulter en ligne.

https://apropos.erudit.org/fr/usagers/politique-dutilisation/ 


\section{In memoriam Elmar Tophoven}

Elmar Tophoven a d'abord été un grand traducteur: celui de Beckett, au premier chef, mais aussi celui du "nouveau roman" français, Nathalie Sarraute, Claude Simon, Robbe-Grillet... Il a également traduit des fragments de Rabelais - admirablement - pour la Compagnie RenaudBarrault. Cette incessante activité de traduction n'a cependant pas absorbé toutes ses énergies: il a fondé le «Collège européen des traducteurs» de Straelen, en Allemagne Fédérale, le premier de ces lieux de rencontre, d'étude et de travail pour traducteurs littéraires qui depuis, à son active instigation, se sont multipliés en Europe. Elmar Tophoven est enfin, et peut-être surtout, le promoteur d'une manière nouvelle de pratiquer la traduction, à la fois plus rigoureuse, plus moderne et plus généreuse. Pas seulement parce qu'il a été le premier à percevoir les merveilleuses potentialités que l'informatique offrait aux traducteurs littéraires. Mais parce qu'il a forgé le concept - et la pratique - de ce qu'il appelait la «traduction transparente». D'une traduction qui, réfléchissant constamment sur elle-même, enregistrant ses étapes, ses phases, ses processus, garde mémoire d'elle-même, et peut, ainsi, à la fois promouvoir - pour la première fois sans doute dans l'Histoire - un échange fécond entre les traducteurs, une transmission d'expérience et, au-delà, permettre, pour la première fois également, un enseignement concret et systématique de la traduction littéraire. Au traducteur «traditionnel», solipsiste et intuitif, Tophoven oppose l'idéal (par lui déjà incarné) d'un traducteur "généreux", soucieux de transmettre son savoir, et systématique dans son agir. Ces idées ont eu un vaste écho dans le monde de la traduction, et elles vont peu à peu - telle est leur force agissante - le révolutionner.

Tout cela n'a pas été sans soulever maintes oppositions et maints conflits, mais l'esprit du travail de Tophoven a d'ores et déjà commencé à transformer et les méthodes et l'esprit même de la traduction littéraire.

Antoine Berman

Centre Jacques-Amyot

Paris 